\title{
Coordinación académica en la Facultad de Estomatología de la Universidad Peruana Cayetano Heredia
}

Ikeda MC, Beltrán RJ. Coordinación académica en la Facultad de Estomatología de la Universidad Peruana Cayetano Heredia. Rev Estomatol Herediana 2005; 15 (2) : 184 - 187.
María Cristina lkeda Artacho' Roberto J. Beltrán Neira ${ }^{2}$

${ }^{1}$ Docente del Departamento Académico de Clínica Estomatológica.

Facultad de Estomatología. Universidad Peruana Cayetano Heredia. ${ }^{2}$ Profesor Emérito.

\section{Correspondencia}

Roberto Beltrán Neira

La conquista 345 Lima 33 - Perú Teléfono: 4368050

e-mail: rbeltran@terra.com.pe

Fecha de Recepción : 20 / diciembre / 2005
A partir del año 1999, la Facultad de Estomatología de la Universidad Peruana Cayetano Heredia (FE-UPCH) puso en práctica un nuevo modelo curricular que denominó Aprendizaje Intensivo a Dedicación Exclusiva (AIDEX) para ser aplicado en los dos primeros años de la carrera. Entre otras particularidades, el modelo contempló el funcionamiento de una coordinación académica, cuya necesidad resultó evidente en razón de las características del modelo, que constituía una importante innovación curricular. En este modelo curricular cada año académico cuenta con un coordinador general de año y con un coordinador por asignatura.

\section{Características del modelo}

1. Las asignaturas se presentan en forma modular. Cada asignatura puede constar de uno o más módulos.

2. Cada módulo de aprendizaje ocupa un determinado tiempo curricular en forma exclusiva, de modo que el alumno se dedica a una sola asignatura durante una o más semanas, según sea la extensión de dicho módulo.
3. Los módulos se organizan en semestres de dieciocho semanas cada uno. En cada semestre se estudian diversas asignaturas, cuya orden secuencial posee una lógica didáctica de acuerdo a una decisión tomada por consenso entre los profesores de las distintas asignaturas. El año académico consta de dos semestres.

4. Cada módulo de aprendizaje está a cargo de un número de profesores, de acuerdo con el número de estudiantes. Por ejemplo, para una promoción de 80 alumnos se tendrá cuatro profesores por asignatura, uno por cada 20 alumnos en las actividades prácticas.

5. Cada grupo de profesores de un determinado módulo de aprendizaje cuenta con su propio coordinador de asignatura, el cual mantiene un contacto frecuente con el coordinador general de año.

6. Las clases expositivas se reducen a un máximo de dos horas por día, el resto del tiempo se dedica a actividades de carácter participativo, como son prácticas de laboratorio, grupos de discusión, actividades de investigación, búsqueda bibliográfica y en multimedios y trabajos de campo. Se trata de obtener aprendizajes en profundidad antes que en extensión.

7. Las asignaturas pertenecen a las áreas académicas de humanidades, ciencias y artes. Los profesores de los distintos módulos se reúnen periódicamente para mantener el mejor balance entre las distintas áreas. Estas reuniones son convocadas y conducidas por el coordinador general de año, tanto a iniciativa propia como a solicitud de los profesores.

8. La dedicación exclusiva a una asignatura por vez facilita la concentración del alumno y evita la competencia por la atención de los alumnos entre las tres áreas académicas, evitando, además, la aglomeración de evaluaciones.

9. Los módulos que pertenecen a un semestre requieren la participación del coordinador general de año a fin de que cada grupo de profesores cumpla con sus contenidos en el tiempo prefijado. 
10. En vista de que cada módulo de aprendizaje está a cargo de varios profesores encargados tanto de las exposiciones como de las prácticas, es preciso coordinar su trabajo para que las actividades marchen sincrónicamente y con el mismo grado de profundidad. Esta coordinación la realiza el coordinador de asignatura con el apoyo del coordinador general de año.

11. La coordinación eficiente de las actividades semestrales, como las de cada asignatura, optimizan el uso del tiempo y los recursos.

12. Cada semestre es planificado antes de su iniciación con la participación de todos los profesores del semestre respectivo.

13. Al término de cada módulo de aprendizaje los profesores entregan un informe de las actividades realizadas y los resultados de la evaluación de los alumnos. En el cuadro de evaluación aparecen todos los calificativos obtenidos, así como el promedio final.

14. Uno de los propósitos del coordinador general de año es promover un clima de relaciones humanas que facilite el proceso enseñanza-aprendizaje. Los profesores se empeñan, tanto en el buen dictado de las asignaturas, como en lograr la confianza de los alumnos.

\section{Funciones de la}

\section{coordinación académica}

1. Reunir al profesorado del semestre entrante con anticipación a fin de planificar el proceso de enseñanzaaprendizaje, lo cual incluye el ordenamiento secuencial de las asignaturas, la distribución del tiempo para cada módulo de aprendizaje, los objetivos y contenidos, las estrategias metodológicas y demás procedimientos expositivos y prácticos, así como la evaluación del aprendizaje. Conviene señalar que, debido al frecuente cambio de profesores, estas reuniones al inicio del semestre resultan muy importantes para la unificación de criterios entre los docentes.

2. Reunir al profesorado de cada módulo de aprendizaje al comienzo y al término del mismo para conocer sus experiencias y opiniones, así como para monitorear el proceso de enseñanza-aprendizaje.

3. Reunir a los representantes de los alumnos para conocer el progreso de los módulos de aprendizaje y tomar conocimiento de las deficiencias que pudieran existir, incluyendo la capacidad didáctica de los profesores y el grado de dificultad que los alumnos encuentran en las asignaturas.

4. Contribuir al planeamiento y coordinación de las actividades de campo, incluyendo la salida de estudios multidisciplinaria anual a una localidad distante de la ciudad.

5. Mantener informado al Decanato y a la Secretaría Académica de la Facultad sobre el desarrollo de los módulos de aprendizaje.

6. Realizar las gestiones que sean necesarias para el buen desarrollo de la docencia, la utilización de los recursos de infraestructura y equipamiento y el cumplimiento en el pago de haberes a los profesores contratados.

7. Promover la interdisciplinariedad y la cooperación entre los distintos grupos de profesores.

8. Escuchar a los profesores que deseen comunicarse con la coordinación de año.

9. Escuchar a los alumnos que deseen comunicarse con la coordinación de año.

10. Facilitar la utilización de la biblioteca de multimedios.

11. Ofrecer una primera orientación a los alumnos respecto de cuestiones administrativas.

12. Recoger al término del año académico la opinión de los alumnos sobre el proceso de enseñanza-aprendizaje recién concluido. Para ello se utiliza una encuesta, que se repite cada año con las mismas preguntas, a fin de poder establecer las comparaciones respectivas.

\section{La experiencia}

La primera actividad después de aprobado el nuevo modelo por el Consejo de Facultad fue la convocatoria a los profesores de las distintas áreas, que se encargarían de las actividades de enseñanza-aprendizaje en los dos primeros años de la carrera. El coordinador general de año, investigador principal del nuevo modelo, expuso las razones por las cuales se pensaba introducir un cambio en el diseño curricular entre ellas, una de las más importantes fue conceder a los módulos de humanidades y artes tiempos exclusivos a fin de que no fueran desatendidos por los alumnos, sabido el menor interés que los alumnos prestan a las asignaturas que consideran de poca importancia para el ejercicio profesional. Los profesores participaron en un taller de cinco días con un total de 30 horas de duración. En este taller se discutieron las bases teóricas que sustentaban la nueva propuesta. Se sometió a crítica algunos conceptos tradicionales, incluyendo: el mito de la clase de 45 minutos, la alternancia de asignaturas en un mismo día o semana, la sacralización de la clase llamada teórica, la desconfianza en la capacidad del alumno para participar activamente en su propia educación y para colaborar con sus compañeros, entre otros. La tipificación del alumno como adulto joven en proceso de transición entre la adolescencia y la adultez fue uno de los elementos orientadores.

Los profesores alcanzaron consenso respecto de las ideas maestras del nuevo modelo curricular. A continuación se puso en discusión la carga horaria de cada asignatura, la ubicación curricular en los dos semestres que conforman el año académico, la metodología de evaluación y los seminarios multidisciplinarios semestrales.

Al término del primer año se recogió la primera encuesta con información cuali-cuantitativa. El análisis de la encuesta fue el componente de opinión de los alumnos que forma parte del libro Aprendizaje Intensivo a Dedicación Exclusiva, de los profesores Roberto J. Beltrán Neira y Eugenio Beltrán Aguilar editado por la Facultad en el año 2003. En los años siguientes se ha continuado recogiendo la opinión de los alumnos sobre los distintos componentes del modelo curricular. Se ha preparado una evaluación comparativa de las encuestas de las distintas promociones 
(1999-2004). A modo de ejemplo relativo al resultado obtenido en las encuestas, se incluye dos figuras de barras : La figura 1 se refiere a la apreciación de los alumnos sobre la calidad educativa de los módulos de cada una de las asignaturas cursadas entre los años 1999 y 2003 (5 promociones), en donde se expresa el porcentaje de aceptación para las opciones "muy buena", "buena" y "regular". La figura 2 muestra la apreciación de los alumnos respecto de las actividades extramurales desarrolladas entre los mismos años; cada barra considera el porcentaje para las opciones "muy bueno", "bueno" y "regular".

\section{Conclusión}

Un modelo educativo complejo, debido a la diversidad de asignaturas y a las limitaciones de tiempo, que requiere la participación de numerosos profesores de áreas diferentes, para atender a promociones numerosas de alumnos recién egresados de la secundaria, necesita un proceso de planificación, ejecución, control y evaluación de un alto grado de precisión. De ahí que el correcto desarrollo del proceso enseñanza-aprendizaje no puede ser dejado al azar o a la improvisación, so pena de pérdida de la calidad que debe caracterizar a la educación universitaria. La ex- periencia obtenida en el proceso de Coordinación Académica desde 1999 a 2005 nos permite remarcar su importancia. Consideramos que la tarea del coordinador general de año y de los coordinadores de asignatura es fundamental para el logro de un proceso de enseñanza-aprendizaje de calidad. Lo observado en el curso de la experiencia realizada permite asegurar que el modelo coordinado de aprendizaje intensivo a dedicación exclusiva constituye una innovación valiosa en el desarrollo curricular en educación universitaria.

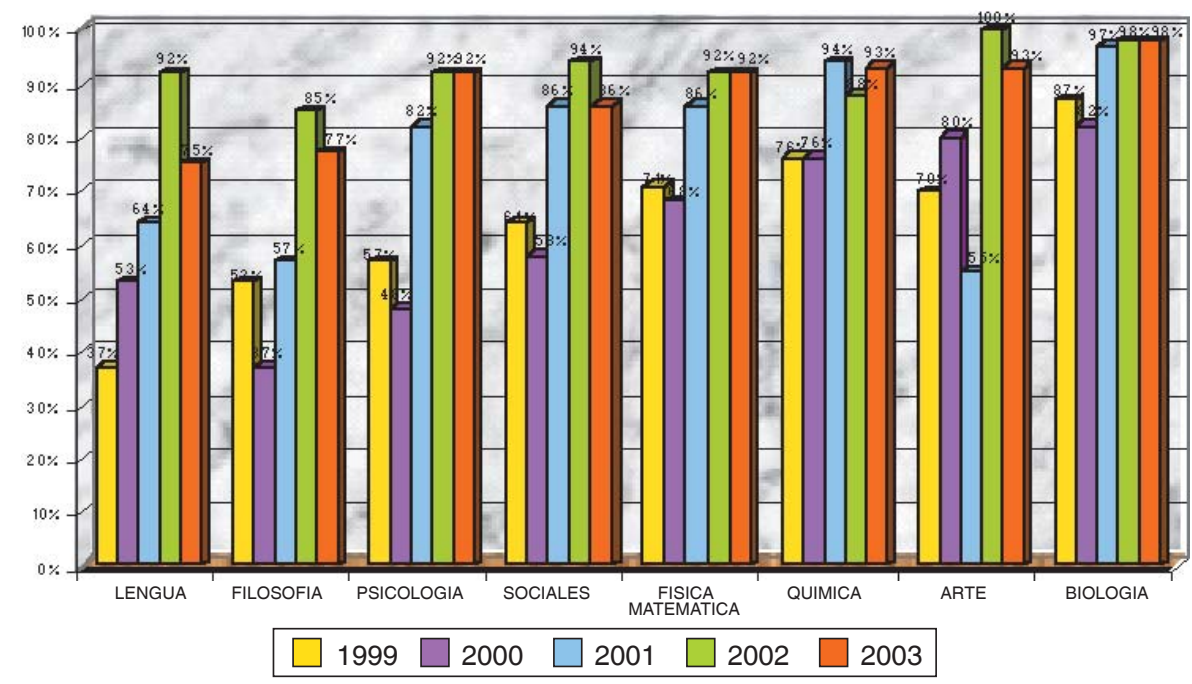

*Los porcentajes expresan para cada año la suma de las opciones "muy bueno", "bueno" y "regular". Fig. 1. Nivel de satisfacción de los cursos modulares del primer año. Facultad de Estomatología-UPCH. 1999-2003.

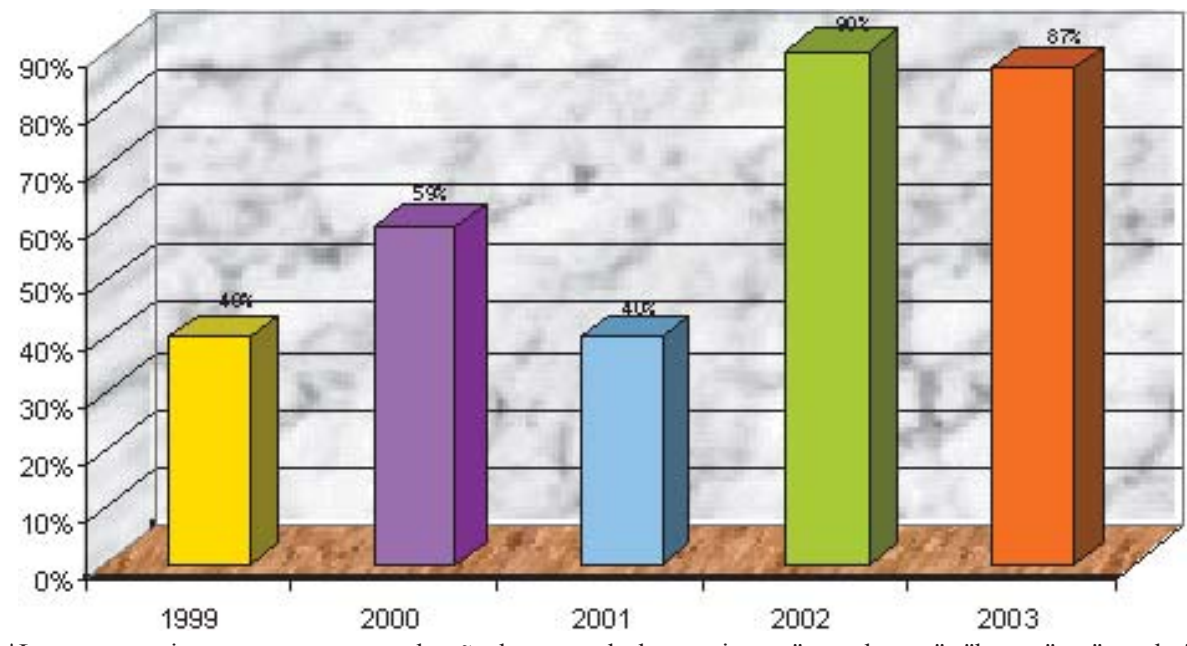

*Los porcentajes expresan para cada año la suma de las opciones "muy bueno", "bueno" y "regular".

Fig. 2. Nivel de satisfacción de las actividades extramurales del primer año. Facultad de Estomatología-UPCH. 1999-2003. 


\section{Referencias bibliográficas}

1. Chambers DW, Glassman P. A primer on competency-based evaluation. J Dent Educ 1997; 61(8):651-66.

2. Marchese TJ. Contexts for competency-based curricula in dental education. J Dent Educ 1994; 58(5):339-41.

3. Whipp JL, Ferguson DJ, Wells LM, Iacopino AM. Rethinking knowledge and pedagogy in dental education. J Dent Educ 2000; 64(12):860-6.
4. Hill J, Houghton P. A reflection on competency-based education: Comments from Europe. J Manag Educ 2001; 25(2):146-166

5. Black S. Learning on the block. Research. American School Board Journal 1998; 185(1): 32-34.

6. Adams DC, Salvaterra ME. Clock Scheduling: Pathways to Success. Lancaster PA: Technomic Publishing Company Inc; 1997. 196 p.

7. Ontoria A, Gómez JPR, Molina A. Potenciar la capacidad de aprender a aprender. Lima: Alfaomega Grupo Editor; 2005. 196 p.

8. Bevenino MM, Snodgrass D, Adams K, Dengel JA. An Educator's Guide to Block Scheduling. Boston: Allyn \& Bacon; 1999.

9. Hottenstein DS. Intensive Schedulling. California: Corwin Press Inc.; 1995.

10. Kaufman A. Implementing ProblemBased Medical Education Lessons from Successful Innovations. New York: Springer Publishing Co.; 1985. 


\section{NORMAS PARA LAS PUBLICACIONES}

La Revista Estomatológica Herediana, tiene las siguientes secciones: Artículos Originales, Reporte de Casos, Artículos de Revisión, Mesa de Debates, Reseña de libros y Resúmenes de artículos.

Los artículos que se presentan para publicación deben ser inéditos, estar escritos en español y se envían al Director de acuerdo a las siguientes normas:

\section{Presentación}

Dos copias del manuscrito escritas a doble espacio en papel blanco ISO A4. - Texto escrito en una sola cara de la hoja.

- Márgenes de 25 mm. interno y externo y $30 \mathrm{~mm}$. superior e inferior.

- Numeración en el ángulo superior derecho de cada página.

- Adjuntar una copia del texto en diskette de 3.5 pulgadas en formato Microsoft Word '97 y las tablas en formato Excel '97.

2. Formato para artículos originales Los artículos deben tener las siguientes partes : título, autores, resumen en español e inglés, palabras claves, texto, referencias, tablas e ilustraciones con leyendas, agradecimientos. Cada uno de estos componentes debe aparecer en una página nueva.

2.1 Título: conciso e informativo (máximo de 50 caracteres incluidos los espacios)

2.2 De los autores:

a.- Apellido paterno, primer nombre e inicial del segundo nombre.

b.- Indicar el grado académico de los autores.

c.- Institución a la que pertenece, y dónde se realizó el estudio.

d.- Nombre, dirección, teléfono y correo electrónico del autor principal.

e.- Fuente de subvención económica para la realización del estudio, si lo hubiera.

2.3 Resúmenes y Palabras Clave

Los resúmenes deben presentarse en español e inglés y no deben contener más de 250 palabras. Las palabras clave deben ser de 3 a 10 palabras. Estas deben ser términos de uso corriente en la literatura científica como los utilizados en el Index Medicus y Dental.

\subsection{Texto}

Los trabajos originales se presentarán divididos en las siguientes secciones : Introducción, material y métodos, resultados, discusión y/o conclusiones. Los reportes de casos y las comunicaciones cortas deben ajustarse al formato de un artículo original. Los artículos de revisión constarán de una presentación concisa de la literatura más reciente sobre el tema que se revisa.

\subsection{Agradecimientos}

Especificarlos en forma sucinta.

\subsection{Referencias}

Enumeradas consecutivamente en orden de aparición en el texto señalados con número arábicos entre paréntesis. Los títulos de revistas deben ser abreviados de acuerdo al estilo utilizado en el Index Medicus. Referir a todos los autores; cuando sean seis o menos; en el caso de haber siete o más autores, referir solo los primeros tres y agregar: et al.

A continuación se dan ejemplos:

Artículo de revistas

You CH, Lee KY, Chey RY, Menguy R. Electrogastrographic study of patients with unexplained nausea, bloating and vomiting. Gastroenterology 1980; 79(5):311-4.

\section{Libros}

Eisen HN. Immunology: an introduction to molecular and cellular principles of the immune response. 5ta. Ed. New York: Harper and Row, 1974:406.

Capítulo en libro

Winstein L, Swartz MN. Pathogenic properties of invading micro-organisms. En: Sodeman WA Jr, Sodeman WA, eds. Pathologic physiology: mechanisms of disease. Philadelphia: WB Saunders, 1974:457-72.

Monografía en una serie

Hunninghake GW, Gadek JE, Szapiel SV, et al. The human alveolar macrophage. En: Harris CC, ed. Cultured human cells and tissues in biomedical research. New York: Academic Press, 1980:54-6(Stoner GD, ed. Methods and perspectives in cell biology; voll).

\section{Tesis o disertación}

Cairns RB. Infrared spectroscopic studies of solid oxygen [Dissertation] Berkeley, California: University of California, 1965. 156 págs.

2.7 Tablas

Presentar las tablas a doble espa- cio en una hoja aparte. Enumerar las tablas consecutivamente en orden de aparición en el texto, con un breve título para cada una de ellas.

Las notas explicatorias deben adjuntarse al pie de la tabla, utilizando los símbolos en el orden siguiente: ${ }^{*},+,+$ $\S,, \emptyset, \#, * *,++$, etc.

\subsection{Ilustraciones}

Las fotografías se presentarán en papel mate, en blanco y negro o color, y deben tener las siguientes medidas: $127 \times 173 \mathrm{~mm}$ y no mayor de $203 \times 254 \mathrm{~mm}$. Las fotografías digitales deberán ser entregadas en formato TIFF con una dimensión mínima de 2.1 MP. En el caso que el autor desee una impresión de las fotos a color, abonará el costo correspondiente. También se aceptarán diapositivas de buena calidad.

Las leyendas deben ser escritas a doble espacio, identificadas con un número arábigo correspondiente a la ilustración. En el caso de microfotografías, especificar la tinción empleada y el aumento correspondiente. Ejemplo: H-E 400X.

\subsection{Unidades de Medida}

Todas las unidades de medida deben ser expresadas en el sistema métrico según el Sistema Internacional de Unidades.

\subsection{Abreviaturas y Símbolos}

El término a abreviarse debe aparecer completo cuando aparece por primera vez, a menos que sea una unidad estándar de medida. Utilizar las abreviaturas aceptadas internacionalmente. Evitar abreviaciones en el título y en el resumen.

\section{Mesa de debates:}

En esta sección se aceptarán temas que reflejen opiniones que puedan ser controversiales, que estimulen la discusión y el planteamiento de alternativas para el desarrollo de la enseñanza en estomatología u odontología.

\section{Separatas:}

Los autores recibirán 10 separatas de sus artículos libres de costo. En caso de requerir una mayor cantidad deberá ser solicitada previamente considerando los siguientes costos:

50 separatas costo :

100.00 Nuevos Soles.

100 separatas costo :

150.00 Nuevos Soles. 